\title{
EFFECT OF MINERAL FERTILIZERS ON FUNGI COMMUNITIES IN A MOLLISOL OF NORTHEAST CHINA
}

\author{
YAN, L. ${ }^{1}-$ WANG, C. ${ }^{1}-$ FENG, G. ${ }^{1}-$ GAO, Q. ${ }^{1 *}-$ ZHANG, J. $^{1 *}-$ WEI, D. ${ }^{2^{*}}$ \\ ${ }^{1}$ Key Laboratory of Sustainable Utilization of Soil Resources in the Commodity Grain Bases of \\ Jilin Province, College of Resource and Environmental Science, Jilin Agricultural University, \\ 130118 Changchun, China \\ (phone: +86-155-2686-6351)
}

${ }^{2}$ Chinese Academy for Environmental Planning, 100000 Beijing, China

*Corresponding authors

e-mail/phone: gaoqinglunwen@163.com/+86-131-3445-7702 (Q. Gao);

zhangjinjing@126.com/+86-132-5260-6675 (J.Zhang); lunwen20189@163.com/+86-173-9099-

8916 (D. Wei)

(Received 1 ${ }^{\text {st }}$ Mar 2019; accepted $3^{\text {rd }}$ May 2019)

\begin{abstract}
The purpose of this research has been to identify the fungi communities abundance and structure of different fertilization management and their relationship with soil environment with 32-year fertilization experiment which included no fertilization (CK), phosphorus plus potassium fertilization (PK) and nitrogen, phosphorus and potassium fertilization (NPK) on Mollisol in Northeast China by pyrosequencing analysis. It was found that mineral fertilizer application caused shifts in the structure of fungi communities. Soil physical and chemical properties and fungi diversity and abundance were significantly affected by long-term mineral fertilization, especially in fungi diversity reduction and soil acidification.
\end{abstract}

Keywords: long-term experiment, diversity, enzyme activity, phylogenetic analysis, CCA analysis

\section{Introduction}

Fertilization has been widely used as a common agricultural practice to maintain soil fertility and increase crop production (Robertson and Vitousek, 2009; Shen et al., 2010). Microbial community composition is sensitive to nitrogen $(\mathrm{N})$, phosphorus $(\mathrm{P})$, and potassium $(\mathrm{K})$ fertilization (Allison and Martiny, 2008), especially in the long-term fertilizer experiments (Shen et al., 2010). $\mathrm{N}$ fertilizer is the limiting nutrient for primary production in many countries. $\mathrm{N}$ input to unmanaged agricultural ecosystem often resulted in microorganism composition and diversity change, which finally impacted microbial and fungi communities (Cleland and Harpole, 2010; Clark et al., 2007). Many researches found that inorganic fertilizer applications change the soil physical and chemical characteristics, such as pH (Tripathi et al., 2012), electrolytic conductivity (EC) (Rezapouret al., 2013) and organic materials concentration (Chávez-Romero et al., 2016; Sul et al., 2013). Furthermore, previous studies have shown that the application of $\mathrm{N}$ fertilizer suppressed microbial activity in soil (Lu et al., 2011; Liu and Greaver, 2010). China began to large-scale application of mineral fertilizer since 1980s, to better understand how Phosphorus plus Potassium (PK) and nitrogen addition (NPK) impact the soil environment in black soil, we have set up a series of long-term fertilizer experiments in order to explore the effect of mineral fertilizer on soil environment and soil quality since 1984.

Previous studies were mainly focused on the impact of long-term fertilization on crop production and microbial communities. However, little information is obtainable about 
the fungi construction and the relationship between fungi community and soil environment under long-term fertilization. In this study, we collected soil samples of three kinds of fertilization management from a 32-year fertilization experiment which included no fertilization (CK), phosphorus and potassium fertilization (PK) and nitrogen, phosphorus and potassium fertilization (NPK) to investigate the effect of different fertilization management on soil fungi communities. The objective of this study was therefore to know the fungi communities abundance and structure of different fertilization management and their relationship with soil environment by pyrosequencing analysis.

\section{Materials and methods}

\section{Sampling site}

Soil samples were collected from long-term fertilizer experiment station in Jilin Agricultural University, Changchun city, Jilin Province, Northeast China $\left(43^{\circ} 26^{\prime} \mathrm{N}\right.$, $\left.125^{\circ} 45^{\prime} \mathrm{E}\right)$. The station was established in 1984 with continuous maize cropping system in a Mollisol. The region was characterized by a temperate continental monsoon climate, with an average annual precipitation of $570 \mathrm{~mm}$ and an average temperature of $4.8^{\circ} \mathrm{C}$. Three fertilization treatments with three replicates for each treatment were selected for the present study, i.e., CK (no fertilizer), PK (phosphorus and potassium fertilization at a rate of $75 \mathrm{~kg} \mathrm{P} / \mathrm{ha}$ and $75 \mathrm{~kg} \mathrm{~K} / \mathrm{ha}$ ), and NPK (nitrogen, phosphorus and potassium fertilization at a rate of $150 \mathrm{~kg} \mathrm{~N} / \mathrm{ha}, 75 \mathrm{~kg} \mathrm{P} / \mathrm{ha}$ and $75 \mathrm{~kg} \mathrm{~K} / \mathrm{ha}$ ). In September 2015, four soil cores from each plot were collected from the top $30 \mathrm{~cm}$ soil layer with auger $(10 \mathrm{~cm}$ diameter) and then mixed into a composite sample. The soil samples were sieved through a $2 \mathrm{~mm}$ sieve, and preserved at $-80^{\circ} \mathrm{C}$ for DNA extraction.

\section{Soil characteristics}

$\mathrm{pH}$ was determined using a glass combination electrode with soil: water of 1:1. Soil organic matter and total $\mathrm{N}$ were determined by the ultraviolet spectrophotometric method, the total phosphorus (TP) were determined using the acidic molybdate-ascorbic acid spectrophotometric method. The initial physical and chemical characteristics of soil in 1983 were shown in Table 1. Catalase and sucrase activity was determined according to Claiborne (1985) and Tabatabai (1977). Phosphatases were analyzed by soil zymography according to Spohn et al. (2013).

Table 1. The basic physical and chemical characteristics of background soil which was tested in 1983 (Lu et al., 2006)

\begin{tabular}{c|c|c|c|c|c|c|c}
\hline $\mathbf{p H}$ & $\begin{array}{c}\mathbf{O M} \\
\mathbf{( g / \mathbf { k g } )}\end{array}$ & $\begin{array}{c}\mathbf{T} \mathbf{N} \\
(\mathbf{g} / \mathbf{k g})\end{array}$ & $\begin{array}{c}\mathbf{T} \mathbf{P} \\
\mathbf{( g / \mathbf { k g } )}\end{array}$ & $\begin{array}{c}\text { Available N } \\
(\mathbf{m g} / \mathbf{k g})\end{array}$ & $\begin{array}{c}\text { Available P } \\
(\mathbf{m g} / \mathbf{k g})\end{array}$ & $\begin{array}{c}\text { Available K } \\
(\mathbf{m g} / \mathbf{k g})\end{array}$ & $\begin{array}{c}\text { Organic C } \\
\mathbf{( g / \mathbf { k g } )}\end{array}$ \\
\hline 7.4 & 22.8 & 1.39 & 0.53 & 125.0 & 13.6 & 218 & 17.90 \\
\hline
\end{tabular}

OM: organic matter; TN: total nitrogen; TP: total phosphorus. Available N: available nitrogen; Available P: available phosphorus; Available K: available potassium; Organic C: organic carbon

\section{Soil DNA extraction}

The DNA was extracted from $0.25 \mathrm{~g}$ soil using the Power soil DNA Isolation Kit (MOBIO Laboratories Inc., Carlsbad, CA, USA) according to the manufacturer's instructions. The DNA samples were purified with Axyprep ${ }^{\mathrm{TM}}$ DNA Gel Extraction Kit. 


\section{ITS gene amplification and sequencing}

To amplify the fungal specific fragments for Miseq, primers ITS1F (5'CTTGGTCATTTAGAGGAAGTAA-3') and ITS2R (5'TCCTCCGCTTATTGATATGC-3') which target for fungal ITS genes were selected. Both forward and reverse primers were tagged with adapter, pad and linker sequences. Each barcode sequence (12 mer) was added to the reverse primer for pooling multiple samples in one run of Miseq sequencing. The PCR conditions were $94{ }^{\circ} \mathrm{C}$ for $2 \mathrm{~min}, 32$ cycles of $94{ }^{\circ} \mathrm{C}$ for $1 \mathrm{~min}, 59{ }^{\circ} \mathrm{C}$ for $45 \mathrm{~s}$ and $72{ }^{\circ} \mathrm{C}$ for $1 \mathrm{~min}$ of extension, followed by $72{ }^{\circ} \mathrm{C}$ for $7 \mathrm{~min}$. PCR products were purified and combined in equimolar rations with the quantitative DNA binding method in order to create a DNA pool that was further used for sequencing from the adaptor. The ITS genes were sequenced using the Illumina Miseq platform. The resultant high-quality sequences were then clustered into operational taxonomic units (OTUs) at 97\% similarity using UPARSE (Edgar, 2013). The RDP fungal ITS database was used as a reference for classification.

\section{Phylogenetic analysis}

After sequencing, the raw fastq files were demultiplexed and quality-filtered using QIIME (version 1.17). As the number of spurious phylotypes increases with sequencing effort, equal number of sequence reads should be used to compare microbial community among samples to minimize the sequencing artifact (Schloss et al., 2011). In this work, about 74503 reads from every sample were randomly picked and grouped into operational units (OTUs) with 97\% similarity cutoff using UPARSE (version 7.1 http://drive5.com/uparse/). Chimeric sequences were identified and removed using UCHIME. Community diversity index (Chao, Simpson, Coverage, Shannon diversity index) and rarefaction curves were generated using the MOTHUR program. The taxonomic assignment of OTUs was performed by RDP Classifier (http://rdp.cme.msu.edu/) against the Warcup fungal ITS database.

\section{Statistical analysis}

Canonical correspondence analyses (CCA) were carried out by Canoco 4.5 to compare the effects of soil characteristics on fungi community structure. Statistical significant analyses were performed by SPSS $(p<0.05)$.

\section{Results and discussion}

\section{Soil characteristics}

After 32 years with different fertilizer application, the physical and chemical properties of soil significantly changed (Table 2). Comparing with the initial soil, the $\mathrm{pH}$ value in the CK treatment only slightly decreased, which was probably attributed to the continuous crop system with no nutrient input. Among the three fertilizer treatments, the $\mathrm{pH}$ value in the NPK treatment was the lowest, indicating that soil acidification occurred. $\mathrm{N}$ additions have resulted in a significant decrease in soil $\mathrm{pH}$ (Guo et al., 2010; Zhou et al., 2016). Stamatiadis (1999) reported that an intensive soil nitrification process resulted in soil acidification which is the main predictor of bacterial diversity in soils (Zhalnina et al., 2015), when amounts of ammonium fertilizer input, especially as $\mathrm{N}$ fertilizer was applied. The content of soil organic matter decreased 
significantly from $22.8 \mathrm{~g} \mathrm{~kg}^{-1}$ to lowest $17.4 \mathrm{~g} \mathrm{~kg}^{-1}$, which resulted from long-term chemical fertilization or no nutrient management without organic materials input. Soil organic carbon also exhibited the same trend. Achiba et al. (2010) showed that manure application could increase soil organic carbon content. Tian (2015) reported the crop straw residue could improve microbial population and increased soil organic carbon content. Comparing with the initial soil, the contents of available $\mathrm{N}$ and $\mathrm{K}$ reduced slightly, while the content of available $\mathrm{P}$ increased remarkably. This indicated that the application of nitrogen and potassium fertilizer was little deficiency and the application of phosphorus fertilizer was in excessive.

Table 2. The physical and chemical characteristics of soil samples in 2015

\begin{tabular}{c|c|c|c|c|c|c}
\hline Treatment & $\mathbf{p H}$ & $\mathbf{O M} \mathbf{( g / \mathbf { k g } )}$ & $\begin{array}{c}\text { Available N } \\
(\mathbf{m g} / \mathbf{k g})\end{array}$ & $\begin{array}{c}\text { Available P } \\
(\mathbf{m g} / \mathbf{k g})\end{array}$ & $\begin{array}{c}\text { Available K } \\
(\mathbf{m g} / \mathbf{k g})\end{array}$ & $\begin{array}{c}\text { Organic C } \\
(\mathbf{g} / \mathbf{k g})\end{array}$ \\
\hline $\mathrm{S}_{0} \mathrm{CK}$ & $7.31 \mathrm{~b}$ & $19.18 \mathrm{a}$ & $92.47 \mathrm{~b}$ & $8.42 \mathrm{c}$ & $162.55 \mathrm{~b}$ & $11.13 \mathrm{a}$ \\
$\mathrm{S}_{0} \mathrm{PK}$ & $7.59 \mathrm{a}$ & $17.43 \mathrm{~b}$ & $88.14 \mathrm{c}$ & $60.57 \mathrm{a}$ & $190.78 \mathrm{a}$ & $10.11 \mathrm{a}$ \\
$\mathrm{S}_{0} \mathrm{NPK}$ & $7.10 \mathrm{c}$ & $20.13 \mathrm{a}$ & $115.67 \mathrm{a}$ & $41.43 \mathrm{~b}$ & $185.13 \mathrm{a}$ & $11.68 \mathrm{a}$ \\
\hline
\end{tabular}

\section{Microbial community diversity}

Illumina Miseq sequencing analysis was performed to investigate the microbial community structure in the three fertilizer treatments. There were 98793, 74503 and 120939 effective sequence tags were observed in the CK, PK and NPK treatment, respectively, with an average red length of $320 \mathrm{bp}$. A total of 74503 reads from each sample were picked randomly for further analysis. The OTUs, richness, diversity, and rerefaction curves of microbial communities were shown in Table 1. A total of 670,618 and 664 OTUs were obtained in CK, PK and NPK treatments, respectively, with clustering at a 97\% similarity level. There are significant differences in the OTUs and Shannon index for different fertilization. PK treatment has less OTUs than the other treatments. The higher the Shannon index, the more the microbial community diversity. Among the three treatments, the Shannon index in the NPK treatment was lower than that in the CK and PK treatments, suggesting that $\mathrm{N}$ addition has significant effect on fungus diversity. Geisseler (2014) reported that increasing N inputs could suppress soil microbial activity according to the meta-analysis of predominantly unmanaged ecosystems (Paungfoo-Lonhienne et al., 2015; Lu et al., 2011; Liu and Greaver, 2010; Theseder, 2008). As one of the most important microbial parameters in soils (Zhang and Cai, 2007; Tian et al., 2015), microbial diversity was affected remarkably by fertilization (Zhang et al., 2012; Esperschuetz et al., 2007).

ITS pyrosequencing method can reveal the differences of soil fungi communities under long-term fertilization. The mean effective reads obtained from the CK, PK and NPK treatments were 98 793, 74503 and 120 939, respectively. The coverage showed that the three fertilization samples were greater than 0.99 , indicating that the sequencing capability was large enough to capture the complete diversity of each sample. Three fertilization treatments had no significant effect on fungi richness, however, balanced fertilization management (NPK) treatment had significantly influenced on fungi diversity according to Shannon indices; and PK treatment remarkably reduced the OTUs number. Fungi diversity is one of the most important fungi parameters in soil (Zhong and Cai, 2007). 


\section{Changes of microbial composition at different levels}

The classifiable sequences in the CK treatment were affiliated with 5 phyla, 19 classes and 125 genera; the classifiable sequence in the PK treatment were affiliated with 6 phyla, 19 classes and 118 genera; and the classifiable sequences in the NPK treatment were affiliated with 5 phyla, 19 classes and 123 genera. The phylogenetic classification of sequences at phylum, class and genus levels from the three treatments was summarized in Figure 1. Ascomycota was the first dominant phyla in all the three treatments, representing $89.13 \%, 86.72 \%$ and $87.70 \%$, respectively. And other main dominant phyla included Basidiomycota, Chytridiomycota, Glomeromycota, and Zygomycota. The rate of Basidiomycota Phylum in the PK and NPK treatments was higher compared with that in the CK treatment, which was favorable to the cultivation of crops and afforestation. Furthermore, the rate of Zygomycota and Chytridiomycota Phylum in the NPK treatment increased two times and five times than that in the others fertilizer treatments.

At class level by the phylogenetic classification, Dothideomycetes and Sordariomycetes are the main compositions in the three fertilizer treatments, followed by Eurotiomycetes, Leotiomycetes and Agaricomycetes. Thus, the long-term application of mineral fertilizers has no significant impacts on fungi community composition, which was consistent with findings from previous studies (Esperschuetz et al., 2007; Ogilvie et al., 2008; Boerjesson et al., 2012). Dothideomycetes Class as the second most abundant Class is very important for ecosystem environment and global carbon cycle by speeding up cell wall decay (Freedman et al., 2015), the results in our research showed that long-term only $\mathrm{P}$ plus $\mathrm{K}$ addition would reduce the composition rate in soil. The application of NPK fertilizer significantly increased Alternaria and Pseudogymnoascus at genus level, compared with the CK and PK treatments. Many pesudogymnoascus species are cellulolytic, function as saprothrophs and are either psychrophilic or psychrotolerant. Alternaria is a genus of ascomycete fungi. Alternaria species are known as major plant pathogens. They are also common allergens in humans, growing indoors and causing hay fever or hypersensitivity reactions that sometimes lead to asthma. At least $20 \%$ of agricultural spoilage is caused by Alternaria species; most severe losses may reach up to $80 \%$ of yield (Nowicki, et al., 2012). The above results indicated that $\mathrm{N}$ fertilizer application could improve the resistance, but also bring about the risk of plant diseases. However, the rate of Fusarium at genus level in the NPK treatment reduced less $70 \%$ than that of the others treatments. Some species in Fusarium genus produce mycotoxins in cereal crops that can affect human and animal health if they enter the food chain. The rate of genus of Penicillium in Eurotiomycetes Class in the NPK treatment obviously increased; on the contrary, the rate of genus of and Ceratobasidium in Agaricomycetes class decreased significantly, comparing with the CK and PK treatments. Penicillium bacteria can decompose many agricultural products, and Gratobasidium cornigerum (Bourd.) Rogers in Ceratobasidium could result in crop banded sclerotial blight. Therefore, suitable $\mathrm{N}$ addition could improve soil ability of degraded cellulose, as well as reduce the chance of plant banded sclerotial blight.

\section{Relationships between fungi community and environmental variables}

According to CCA analysis, catalase had large variance inflation factor (VIF), which implied that its variables are redundant with other variables in the environmental factors 
(Fig. 2). All the environmental variables together explained $99.3 \%$ of the variation in fungi communities among fertilizer treatments. A total of $32.2 \%$ of the total variance were explained by the first two constrained axes of CCA analysis, in which the first axis explaining $23.0 \%$ and second explaining $8.9 \%$ of the total variance. The CCA clearly demonstrates that Pseudogymnoascus, Alternaria, Penicillium and Chaetomium are sensitive to $\mathrm{N}$ fertilizer application.

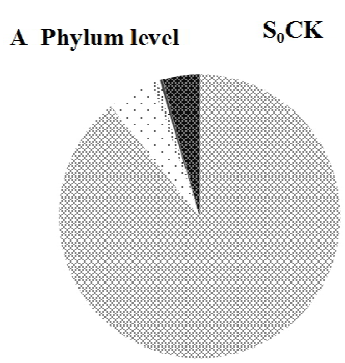

B Class level $\quad \mathrm{S}_{0} \mathrm{CK}$

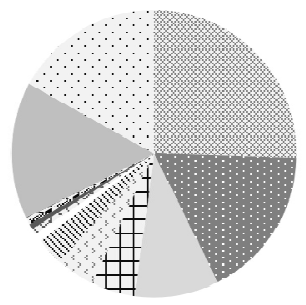

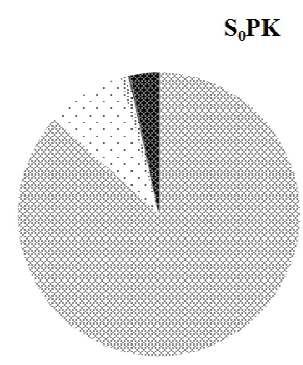

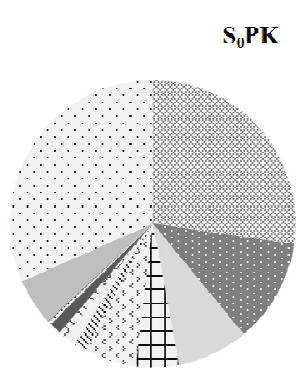

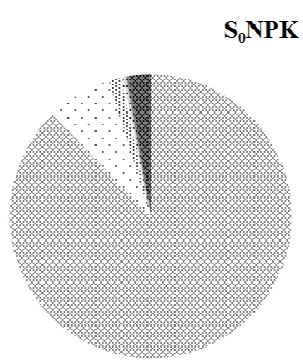

$\mathbf{S}_{0} \mathbf{N P K}$

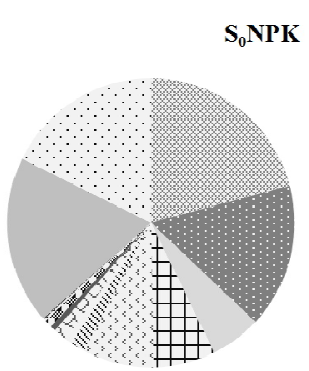

Ascomycota

Basidiomycota

it: Zygomycota

Glomeramycota

Unclassified phylum

: Chytridiomycota

兴 Other

\& Sordariomycetes Dothideomycetes Eurotiomycetes

I Leotiomycetes

. Agaricomycetes

Incertae_sedis_14

Pezizomycetes

Incertae_sedis_10

Orbiliomycetes

- Glomeromycetes

Chytridiomycetes
Microbotryomycetes

Lecanoromycetes

Agaricostilbomycetes

- Cystobasidiomycetes

Other

Unclassified class

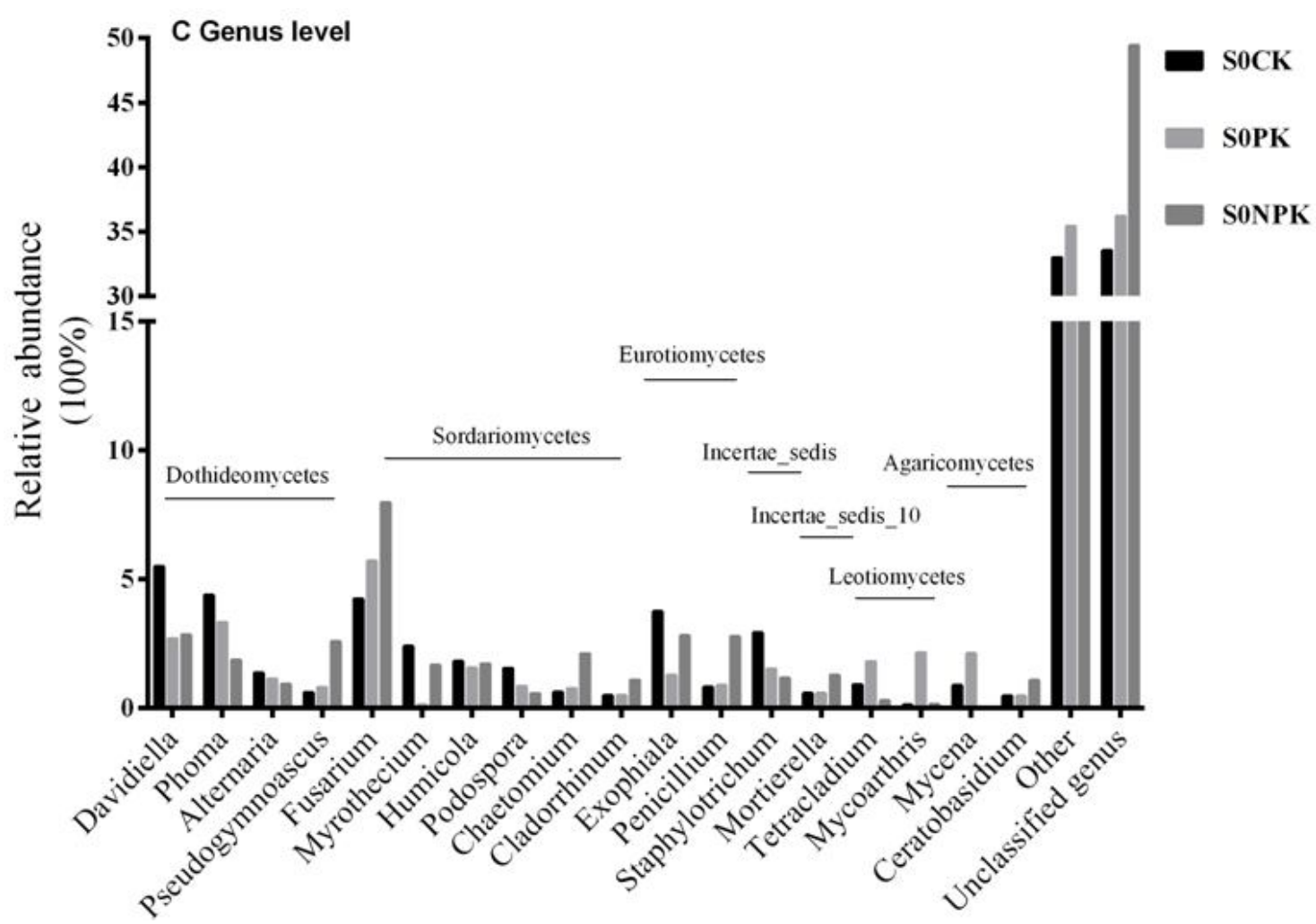

Figure 1. Fungal community structures at (A) Phylum level, (B) Class and (C) genus level of the SoCK, SoPK and SoNPK. The relative abundance was defined as the percentage of the in total effective fungal sequences in sample. Genera making up less than $1 \%$ of total composition was classified as 'other' 


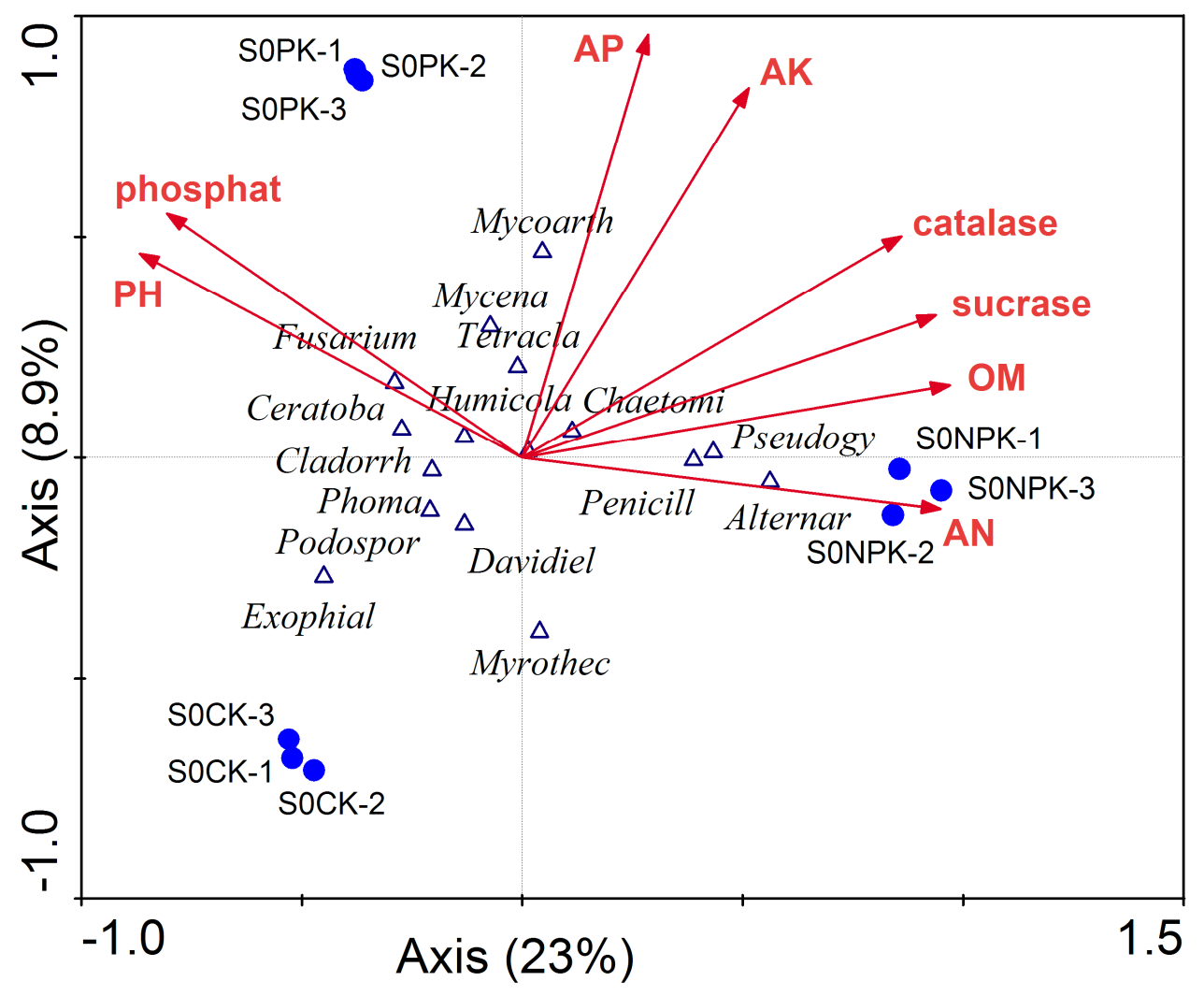

Figure 2. CCA analysis of different fertilization treatments with soil environmental characteristics as arrows. Triangle symbols represent different genus fungal community structures. OM: organic matter; AN: available nitrogen; AP: available phosphorus; AK: available potassium

\section{Conclusion}

The results presented in this paper unequivocally demonstrate that mineral fertilizer application caused shifts in the structure of fungi communities in Mollisol soil. Soil physical and chemical properties and fungi diversity and abundance were significantly affected by long-term mineral fertilization, especially in fungi diversity reduction and soil acidification.

Acknowledgements. The authors would like to acknowledge the Technology Key Project of Jilin Province (20170101004JC), National Key Research and Development Program of China (2017YFD0201804), and Project supported by the National Natural Science Foundation of China (Grant No.31301850) for their financial support.

\section{REFERENCES}

[1] Achiba, W. B., Lakhdar, A., Gabteni, N., Laing, G. D., Verloo, M., Boeckx, P., Cleemput, O. V., Jedidi, N., Gallali, T. (2010): Accumulation and fractionation of trace metals in a Tunisian calcareous soil amended with farmyard manure and municipal solid waste compost. - Journal of Hazardous Materials 176: 99-108. 
[2] Allison, S. D., Martiny, J. B. H. (2008): Resistance, resilience, and redundancy in microbial communities. - Proceedings of the National Academy of Sciences of the USA 105: 11512-11519.

[3] Boerjesson, G., Menichetti, L., Kirchmann, H., Kaetterer, T. (2012): Soil microbial community structure affected by 53 years of nitrogen fertilization and different organic amendments. - Biology \& Fertility of Soil 48: 245-257.

[4] Chávez-Romeroa, Y., Navarro-Noyab, Y. E., Reynoso-Martíneza, S. C., Sarria-Guzmána, Y., Govaertsc, B., Verhulstc, N., Dendoovena, L., Luna-Guido, M. (2016): 16s metagenomics reveals changes in the soil bacterial community driven by soil organic $\mathrm{c}, \mathrm{n}-$ fertilizer and tillage-crop residue management. - Soil and Tillage Research 159: 1-8.

[5] Claiborne, A. (1985): Catalase Activity - In: Greenwald, R. A. (ed.) CRC Handbook of Methods for Oxygen Radical Research. CRC Press, Boca Raton, FL.

[6] Clark, C. M., Cleland, E. E., Collins, S. L., Fargione, J. E., Gough, L., Gross, K. L., Pennings, S. C., Suding, K. N., Grace, J. B. (2007): Environmental and plant community determinants of species loss following nitrogen enrichment. - Ecology Letters 10: 596607.

[7] Cleland, E. E., Harpole, W. S. (2010): Nitrogen enrichment and plant communities. Annals of the New York Academy of Sciences 1195: 46-61.

[8] Edgar, R. C. (2013): UPARSE: highly accurate OTU sequences from microbial amplicon reads. - Nat Methods 10: 996-998.

[9] Esperschuetz, J., Gattinger, A., Maeder, P., Schloter, M., Fliessbach, A. (2007): Response of soil microbial biomass and community structures to conventional and organic farming systems under identical crop rotation. - FEMS Microbiology Ecology 61: 26-37.

[10] Freedman, Z. B., Romanowicz, K. J., Upchurch, R. A., Zak, D. R. (2015): Differential responses of total and active soil microbial communities to long-term experimental $\mathrm{N}$ deposition. - Soil Biology and Biochemistry 90: 275-282.

[11] Geisseler, D., Scow, K. M. (2014): Long-term effects of mineral fertilizers on soil microorganisms -A review. - Soil Biology and Biochemistry 75: 54-63.

[12] Guo, J. H., Liu, X. J., Zhang, Y., Shen, J. L., Han, W. X., Zhang, W. F., Christie, P., Goulding, K. W. T., Vitousek, P. M. Zhang, F. S. (2010): Significant acidification in major Chinese croplands. - Science 327: 1008-1010.

[13] Liu, L., Greaver, T. L. (2010): A global perspective on belowground carbon dynamics under nitrogen enrichment. - Ecology Letters 13: 819-828.

[14] Lu, H. Y., Li, N. (2006): effect of long-term fixed position fertilization on nutrition in topsoil of black earth. - Journal of Jilin Agricultural Sciences 31: 33-36 (in Chinese with English abstract).

[15] Lu, M., Yang, Y., Luo, Y., Fang, C., Zhou, X., Chen, J., Yang, X., Li, B. (2011): Responses of ecosystem nitrogen cycle to nitrogen addition: a meta-analysis. - New Phytologist 189: 1040-1050.

[16] Nowichi, M., Nowakowska, M., Niezgoda, A., Kozik, E. U. (2012): Alternaria black spot of crucifers: symptoms, importance of disease, and perspectives of resistance breeding. Vegetable Crops Research Bulletin 76: 5-19.

[17] Ogilvie, L. A., Hirsch, P. R., Johnston, A. W. B. (2008): Bacterial diversity of broadbalk 'Classical' winter wheat experiment in relation to long-term fertilizer inputs. - Microbial Ecology 56: 525-537.

[18] Paungfoo-Lonhienne, C., Yeoh, Y. K., Kasinadhuni, N. R., Lonhienne, T. G., Robinson, N., Hugenholtz, P., Ragan, M. A., Schmidt, S. (2015): Nitrogen fertilizer dose alters fungal ommunities in sugarcane soil and rhizosphere. - Scientific Report 58678: 1-6.

[19] Rezapour, S., Taghipour, A., Samadi, A. (2013): Modififications in selected soil attributes as inflfluenced by long-term continuous cropping in a calcareous semiarid environment. - Nat. Hazards 69: 1951-1966.

[20] Robertson, G. P., Vitousek, P. M. (2009): Nitrogen in agriculture: balancing the cost of an essential resource. - Annual Review of Environment and Resources 34: 97-125. 
[21] Shen, J. P., Zhang, L. M., Guo, J. F., Ray, J. L., He, J. Z. (2010): Impact of long-term fertilization practices on the abundance and composition of soil bacterial communities in Northeast China. - Applied Soil Ecology 46: 119-124.

[22] Spohn, M., Kuzyakov, Y. (2013): Distribution of microbial and root-derived phosphates activities in the rhizosphere depending on $\mathrm{P}$ availability and $\mathrm{C}$ allocation - coupling soil zymography with ${ }^{14} \mathrm{C}$ imaging. - Soil Biology and Biochemistry 67: 106-113.

[23] Stamatiadis, S., Werner, M., Buchanan, M. (1999): Field assessment of soil quality as affected by compost and fertilizer application in a broccoli field (San Benito County, California). - Applied Soil Ecology 12: 217-225.

[24] Sul, W. J., Asuming-Brempong, S., Wang, Q., Tourlousse, D. M., Penton, C. R., Deng, Y., Rodrigues, J. L. M., Adiku, S. G. K., Jones, J. W., Zhou, J., Cole, J. R., Tiedje, J. M. (2013): Tropical agricultural land management influences on soil microbial communities through its effect on soil organic carbon. - Soil Biol. Biochem. 65: 33-38.

[25] Tabatabai, M. A. (1977): Effects of trace elements on urease activity in soils. - Soil Biology \& Biochemistry 9: 9-13.

[26] Tian, W., Wang, L., Li, Y., Zhuang, K. M., Li, G., Zhang, J. B., Xiao, X. J., Xi, Y. G. (2015): Responses of microbial activity, abundance, and community in wheat soil after three years of heavy fertilization with manure-based compost and inorganic nitrogen. Agriculture Ecosystems and Environment 213: 219-227.

[27] Treseder, K. K. (2008): Nitrogen additions and microbial biomass: a meta-analysis of ecosystem studies. - Ecology Letters 11: 1111-1120.

[28] Tripathi, B. M., Kim, M., Singh, D., Lee-Cruz, L., Lai-Hoe, A., Ainuddin, A. N., Go, R., Rahim, R. A., Husni, M. H. A., Chun, J., Adams, J. M. (2012): Tropical soil bacterial communities in Malaysia: $\mathrm{pH}$ dominates in the Equatorial Tropics too. - Microb Ecol 64: 474-484.

[29] Zhalnina, K., Dias, R., de Quadros, P. D., Davis-Richardson, A., Camargo, F. A., Clark, I. M., McGrath, S. P., Hirsch, P. R., Triplett, E. W. (2015): Soil pH determines microbial diversity and composition in the park grass experiment. - Microbial Ecology 69: 395406.

[30] Zhang, Q. C., Ahamsi, I. H., Xu, D. T., Wang, G. H., Lin, X. Y., Jilani, G., Hussain, N., Nawaz, A. (2012): Chemical fertilizer and organic manure inputs in soil exhibit a vice versa pattern of microbial community structure. - Applied Soil Ecology 57: 1-8.

[31] Zhong, W. H., Cai, Z. C. (2007): Long-term effects of inorganic fertilizers on microbial biomass and community functional diversity in a paddy soil derived from quaternary red clay. - Applied Soil Ecology 36: 84-91.

[32] Zhou, J., Jiang, X., Zhou, B., Zhao, B., Ma, M., Guan, D., Qin, J., Chen, S., Cao, F., Shen, D., Li, J. (2016): Thirty four years of nitrogen fertilization decreases fungal diversity and alters fungal community composition in black soil in northeast China. - Soil Biology and Biochemistry 95: 135-143. 